\title{
موقف الأصمعي من الشعر في صدر الإسلام
}

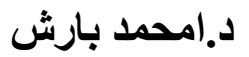 \\ كلية الآداب و اللغة العربية \\ جامعة قسنطينة
}

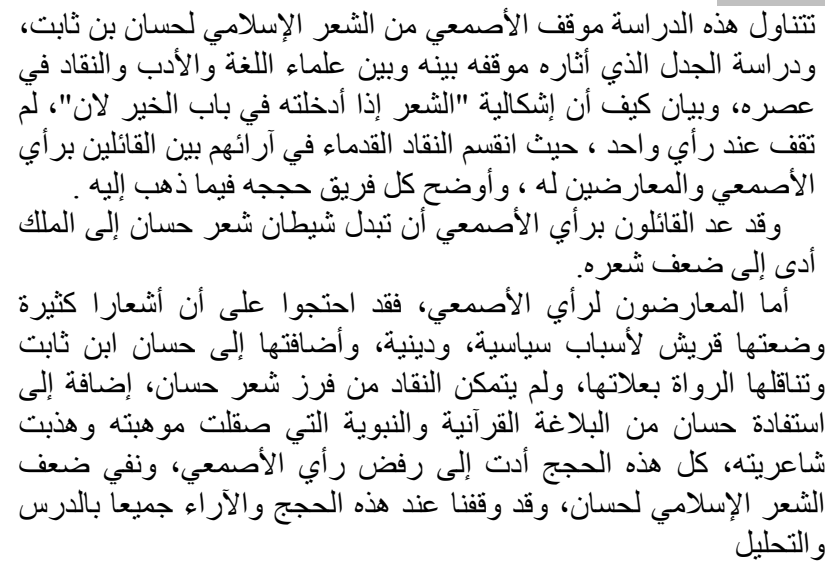

\begin{abstract}
:
This study deals with the position of Al-Asma'i of the Islamic poetry of Hassan ibn Thabit and the study of the controversy aroused by his position with linguists and critics of his time. And to explain how the problem of "poetry if you enter the door of good because" did not hold the opinion of one, where critics were divided in their opinions among those who say All these arguments led to rejection of the author's opinion and denied the weakness of Hassan's Islamic poetry, and we held these arguments and opinions on study and analysis, and those who denigrated him, and each team explained their arguments in what had gone to him.

Those who say in the opinion of Al-Asma'i said that the demon of Hasan's poetry was turned into a king, which led to the weakness of his poetry. As for the denigrators, they protested that the many poems developed by the Quraish for political and religious reasons, and were written for Hassan Ibn Thabit and were narrated with his defects. The critics were not able to sort Hassan's poetry, in addition to benefiting Hassan from the Quranic rhetoric and that of the prophet who refined his talent and poetics. All these arguments have led to the rejection of Al-Asma'i's opinion, and have denigrated the weakness of Hassan's Islamic poetry, and we have studied all these arguments and opinions through analysis.
\end{abstract}


وقد أر اد النقاد من خلال اهتماهمه بمقولة الأصمعي أن لا تقف عند رأي واحد ، فاستمر الجدل بينهم

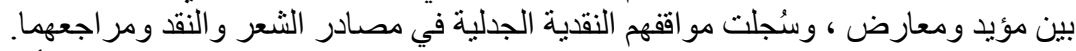

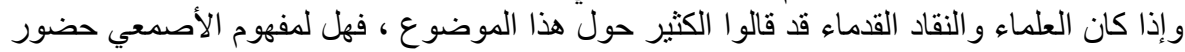

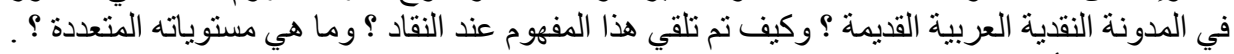

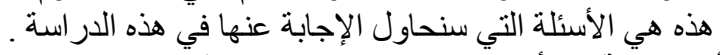

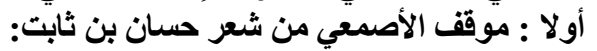

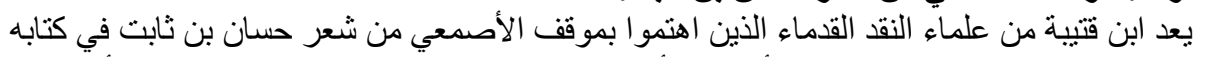

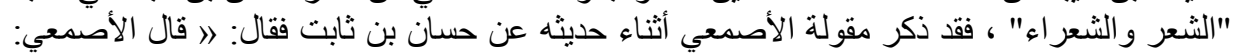

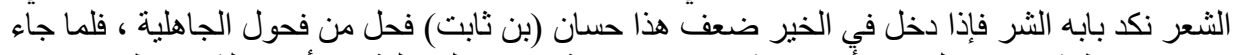

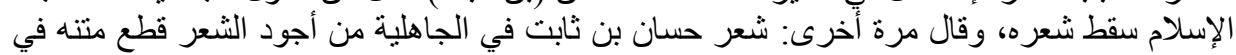

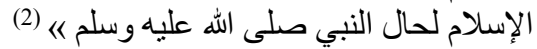

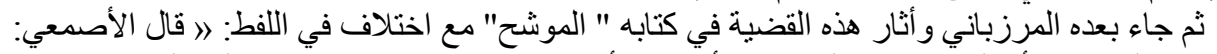

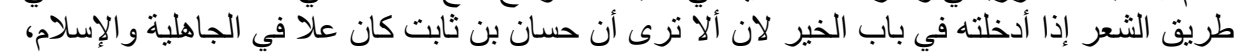

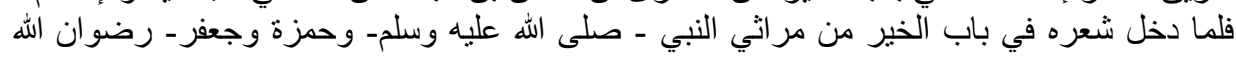

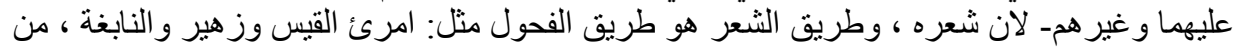

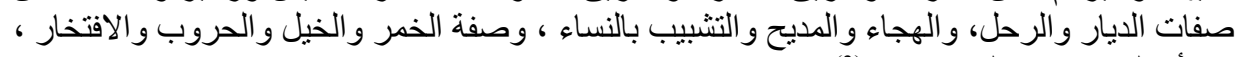

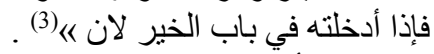

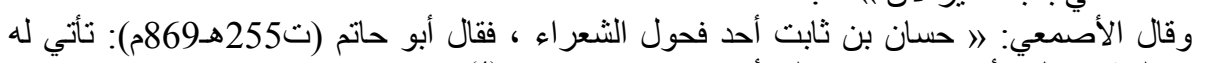

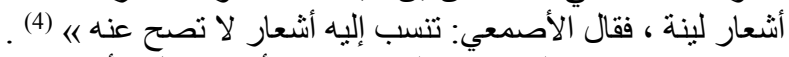

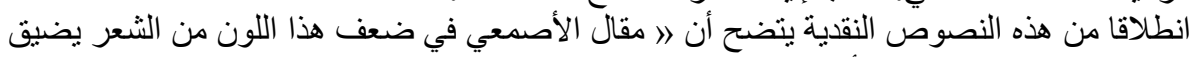

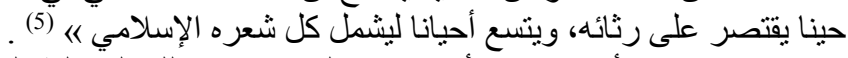

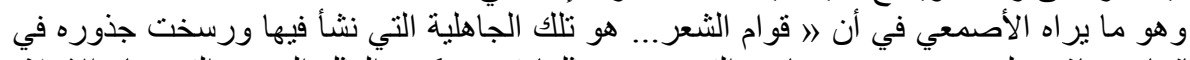

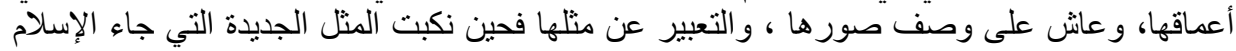

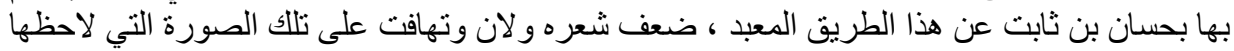

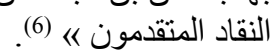

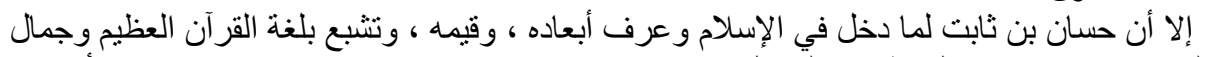

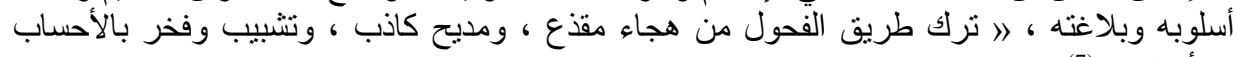

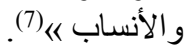

وحسب هذا الر أي فقد أراد حسان أن ينهج نهجا جديدا للفحولة وفق القيم الأدبية الجديدة التي فرضها

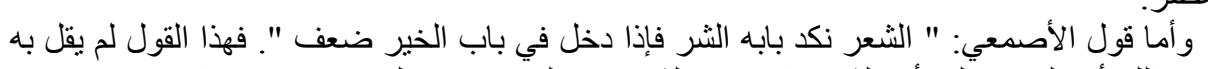

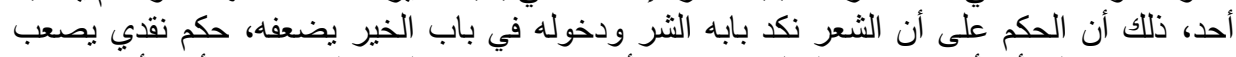

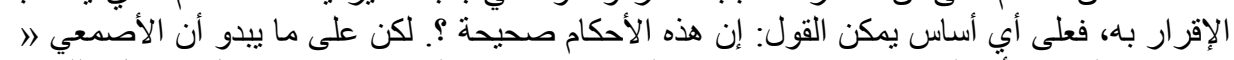

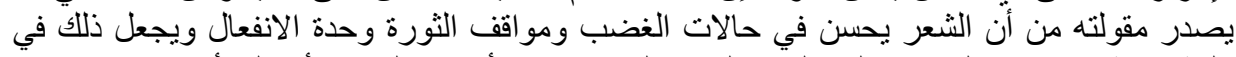

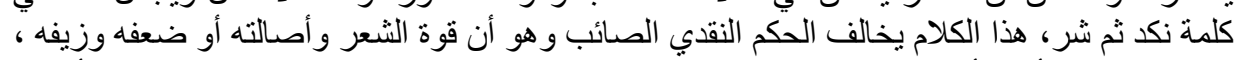

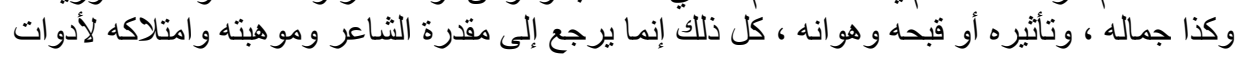

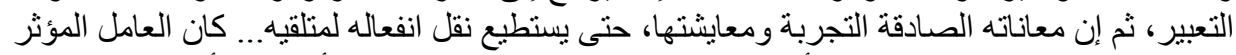

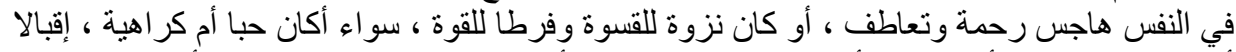

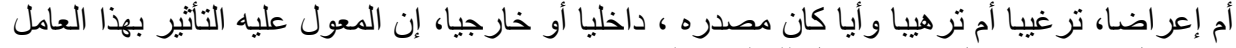

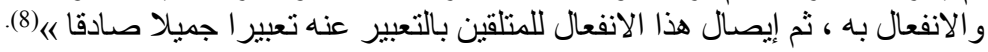


وبالتالي فإن الحكم بأن الدين أو الخير، أدى كل منهما إلى ضعف شعر حسان حسان ، فهو حكم غير صحيح

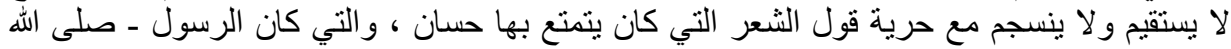

عليه وسلم- يطرب لألها.

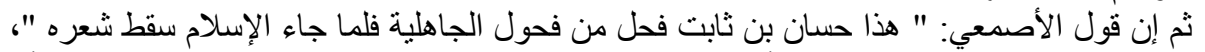

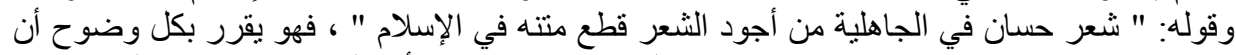

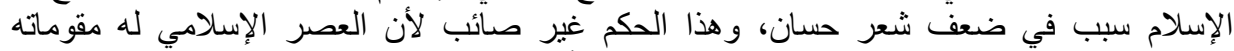

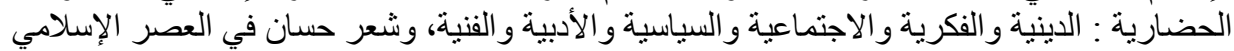

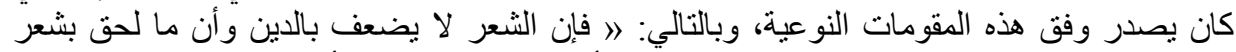

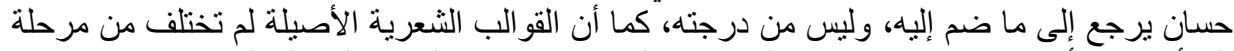

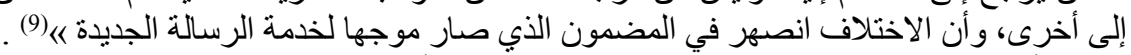

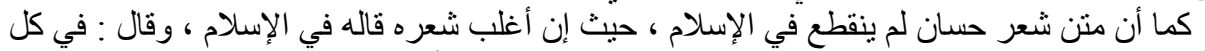

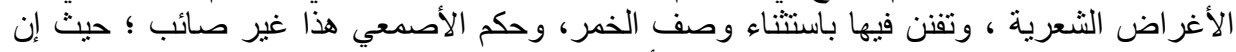

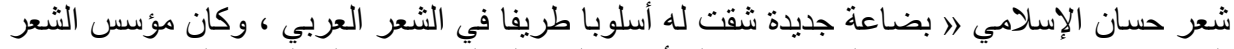

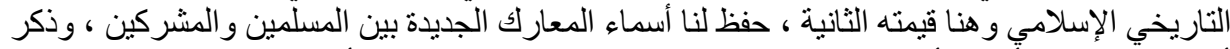

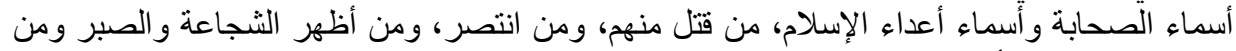

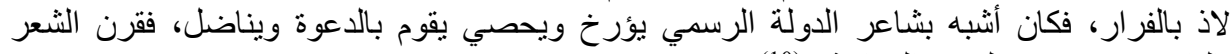

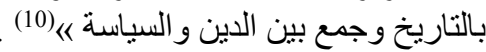

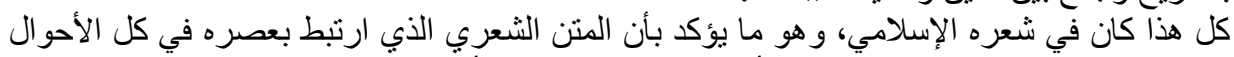

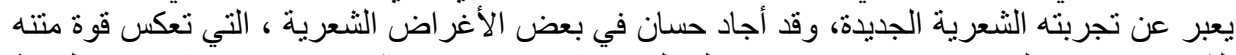

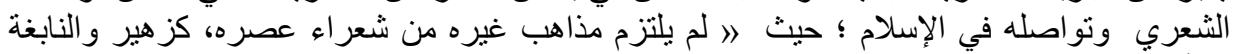

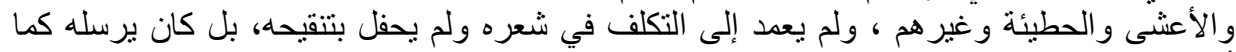

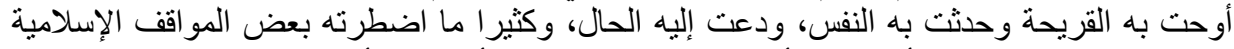

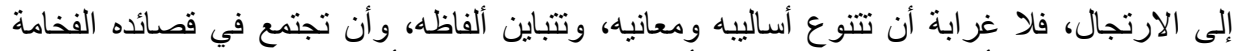

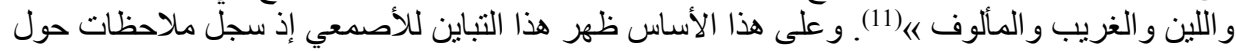

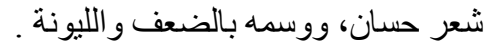

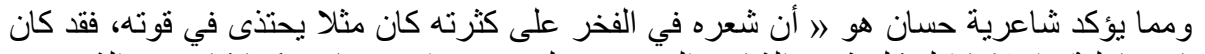

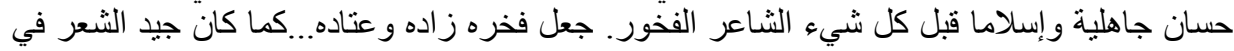

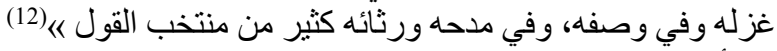

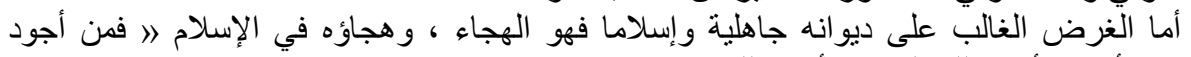

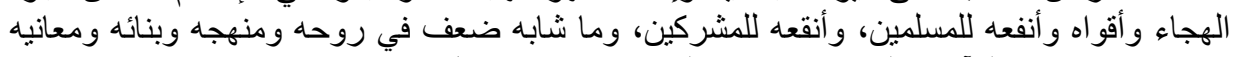

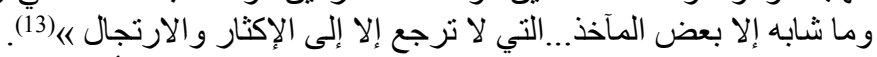

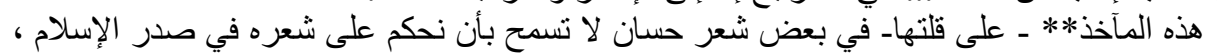

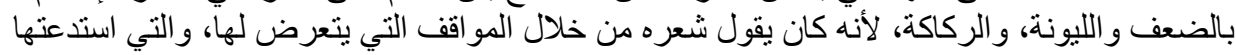

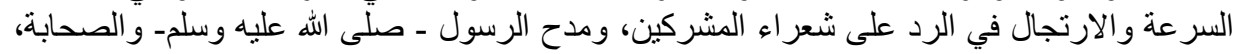

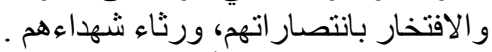

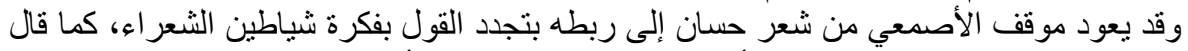

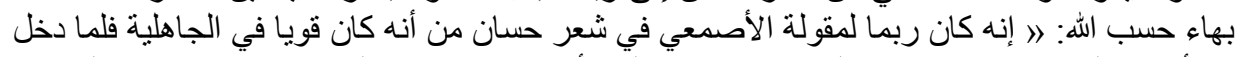

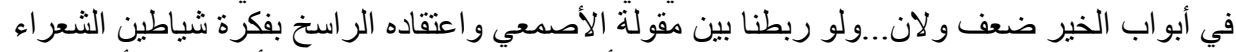

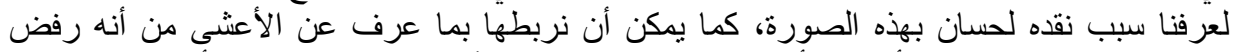

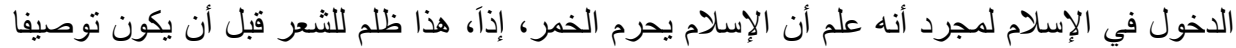

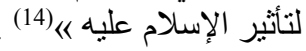




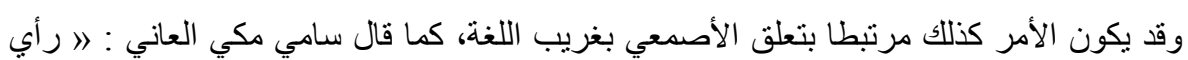

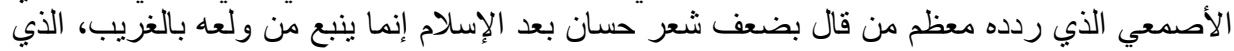

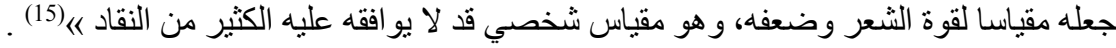

ثانيا: تلقي بعض النقاد لفكرة الأصمعي :

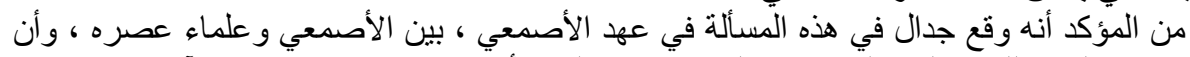

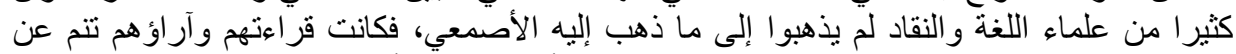

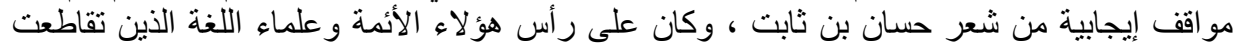

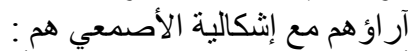

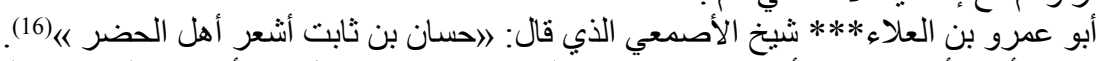

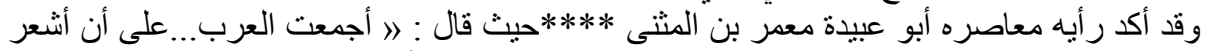

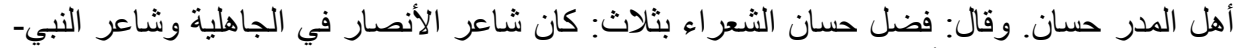

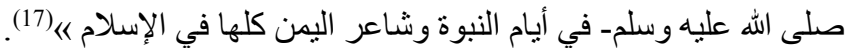

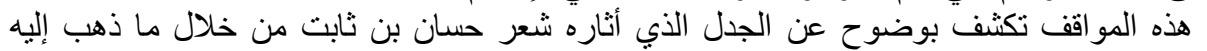

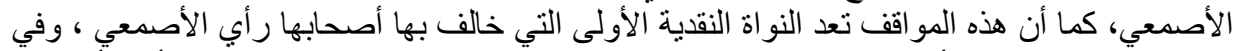

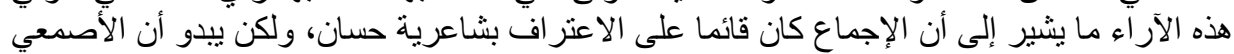

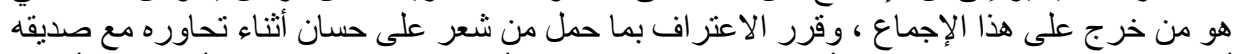

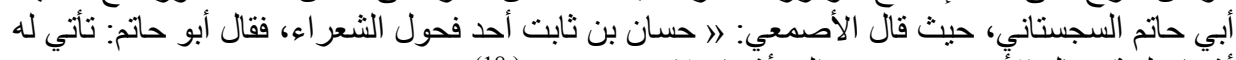

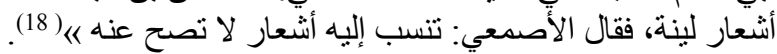

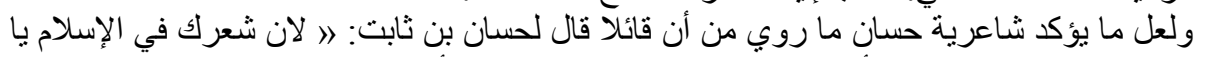
أبا الحسام ، فقال للقائل: يا ابن أخي ، إن الإسلام يحجز عن الكذب أو يمنع من الكذب ، وإن وإن الثنعر يزينه الإنلان

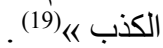
وقد علق القرطبي على موقف حسان هذا فقال: 》ا يعني إن شأن التجويد في الثعر الإفراط في الوصف والتزيين بغير الحق عال (20).

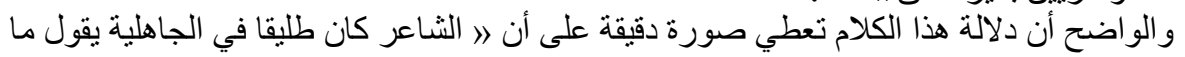

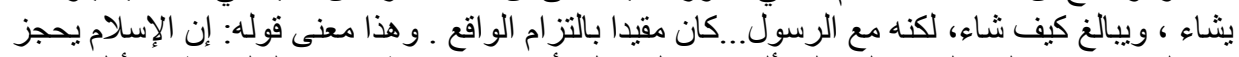

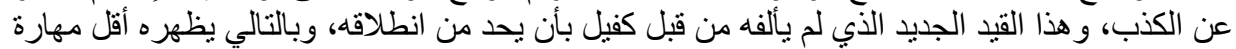

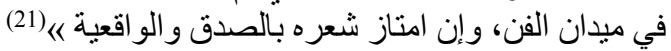

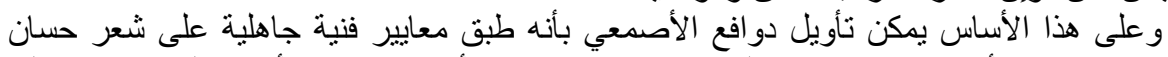

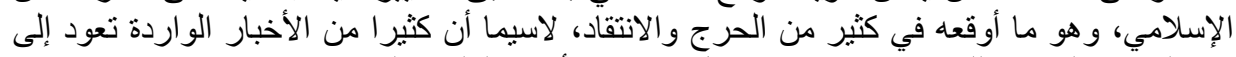

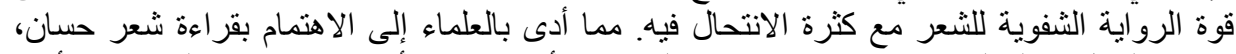

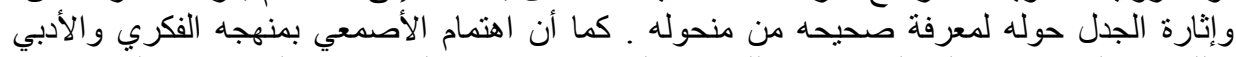

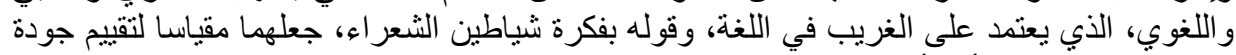

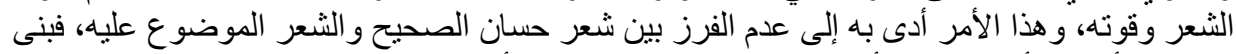

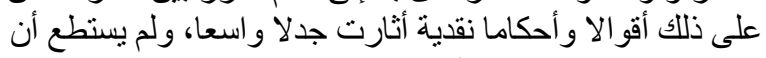

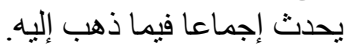

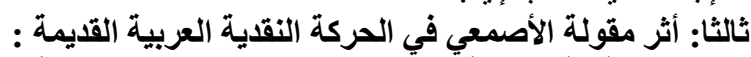

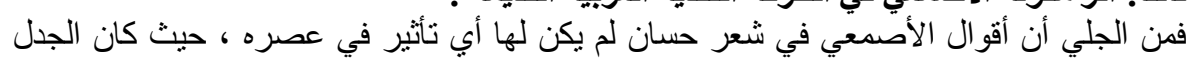

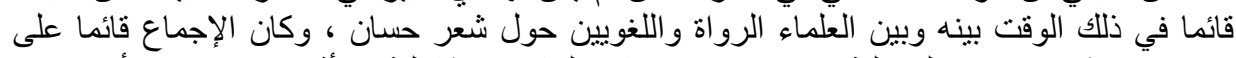

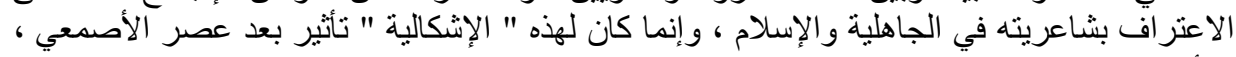

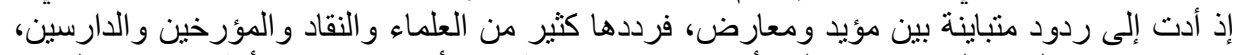
و اتضح من خلال تداولها في كتب النقد أن شعر حسان بن ثابت الأنصاري كان الأن الأكثر اهتماما بالدرس 
النقدي من طرف النقاد، كما نتج عن ذلك أراء و أحكام نقدية ماز الت آثار ها تتجدد في الدرس النقدي، إلى

أدى مفهوم الأصمعي لشعر حسان إلى جدل نقدي و إلى تشكيل موقفين نقديين بارزين، وردود ألثاد أفعال يومنا هذا.

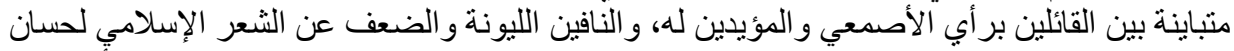

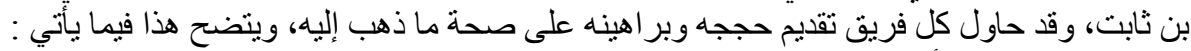
1 - 1 حجج المؤيدين للأصمعي :

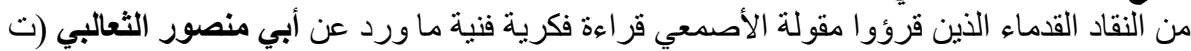

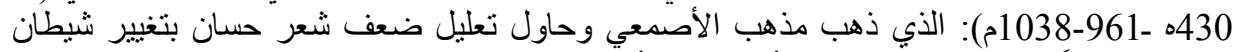

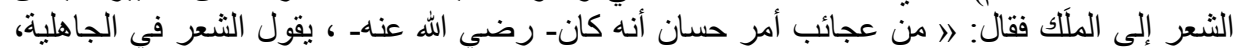

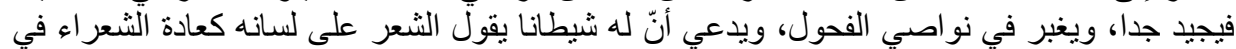

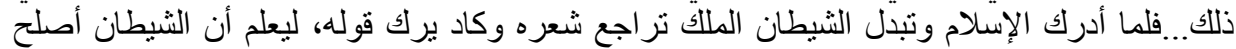

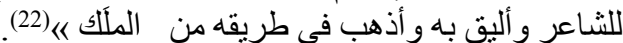
إن النظرة النقدية إلى شيطان الثعر هي الثئ نظرة فنية جاهلية قديمة، حيث كان الاعتقاد سائدا بأن

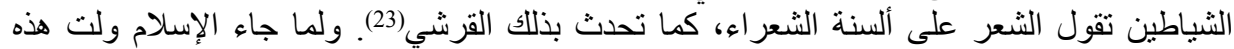

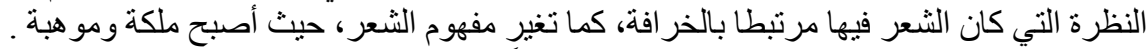

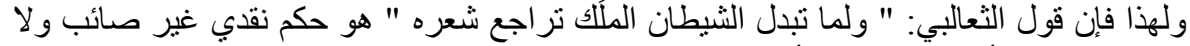

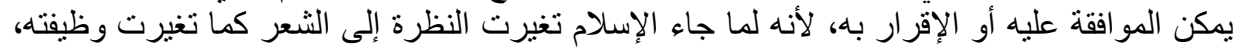

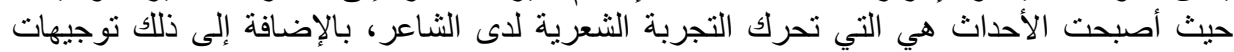

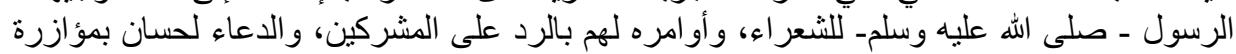

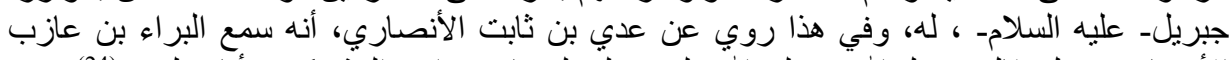

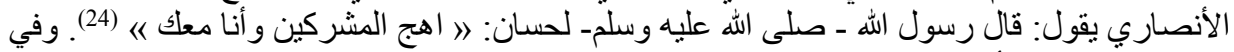

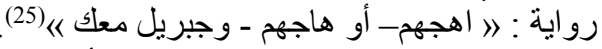

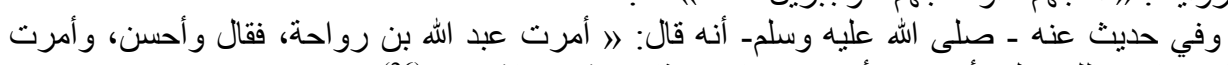

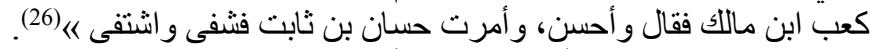

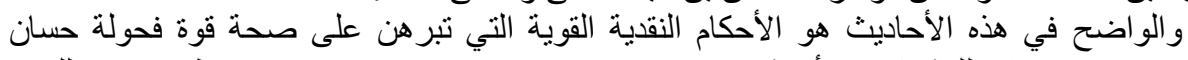

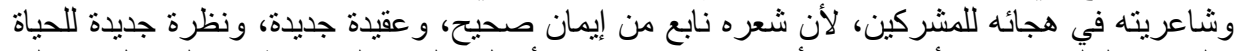

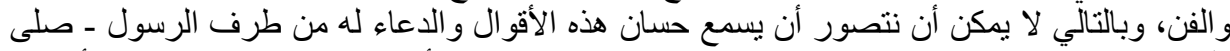

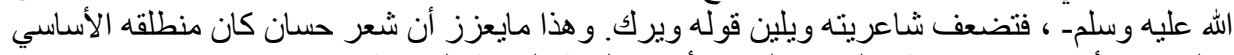

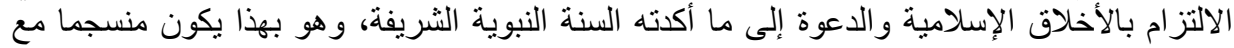

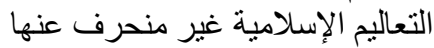

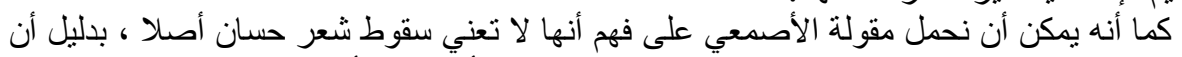

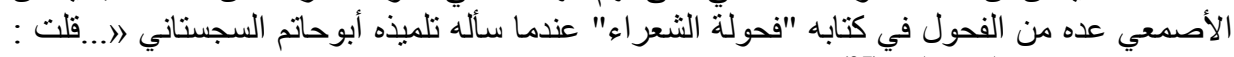

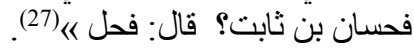
و وككذا يمكنتا أن نعد إقرار الأصمعي نفسه بفحولة حسان دليلا على عدم وضوح مقولته عند النقاد . 2- 2 حجج الر افضين لرأي الأصمعي :

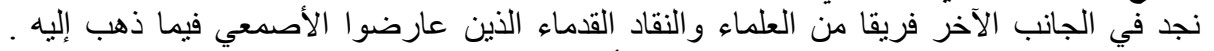

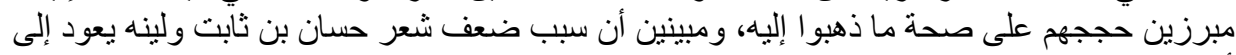

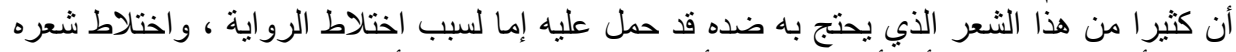

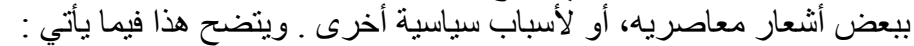

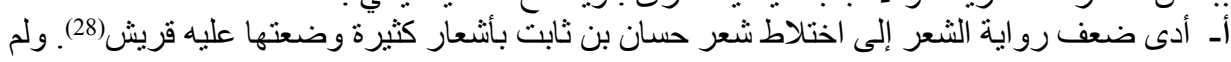

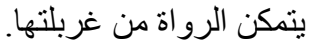


بــ يعد كلام الثعر اء الإسلاميين ومن بينهم حسان، أعلى طبقة في البلاغة من الجاهليين، في منثور هم ومنظومهم وذللك لأخذهم بأسلوب القرآن آن وبلاغته (29).

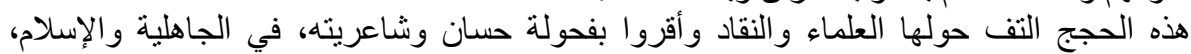

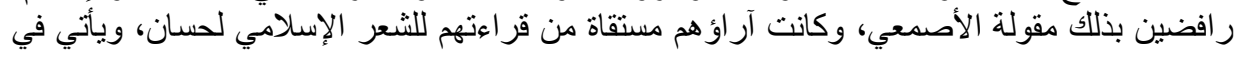

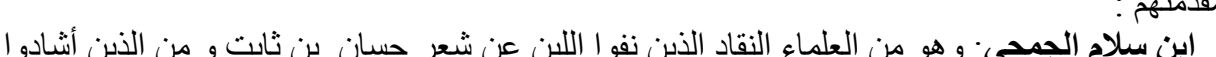

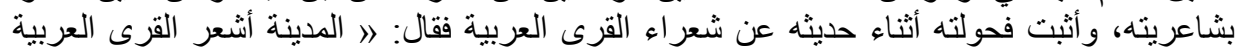

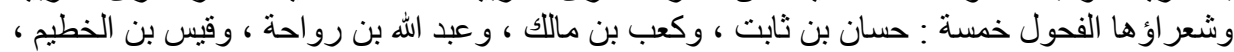

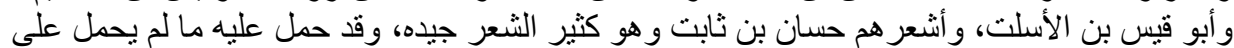

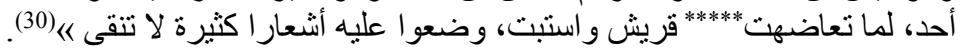

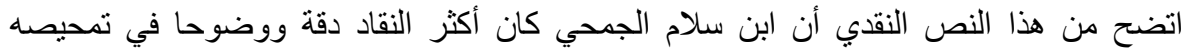

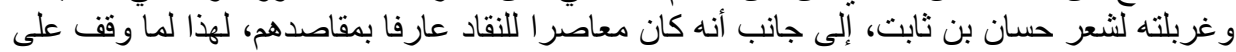

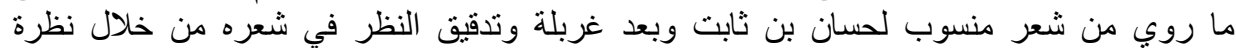

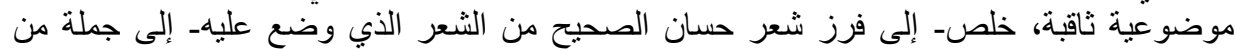

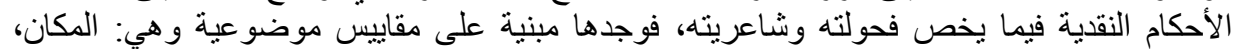

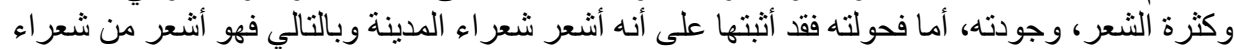

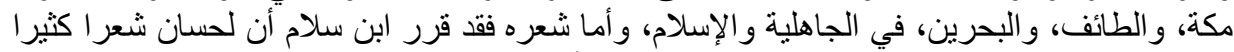

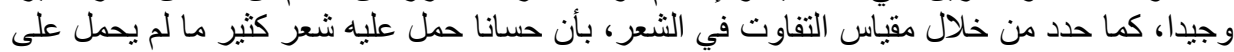

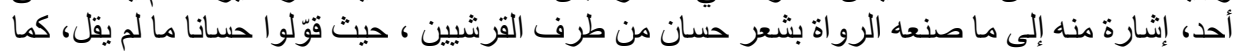

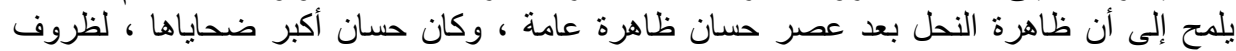

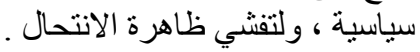

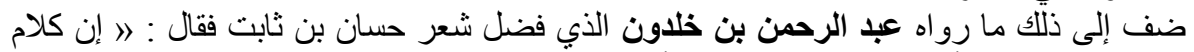

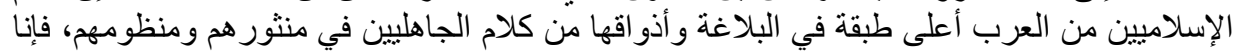

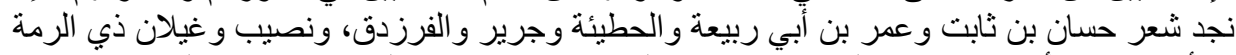

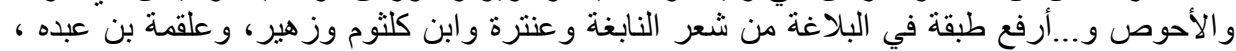

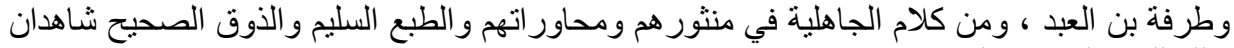
بذلك اللناقد البصير بالبلاغة. و السبب في ذلك أن هؤلاء الذين أدركوا الإسلام وسمعوا الطبقة العالية من الكلام في القرآن وآن والحديث

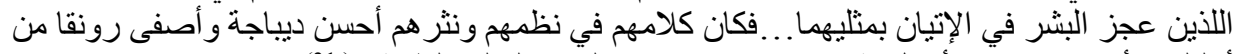

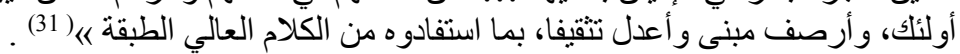

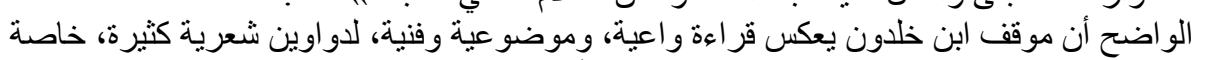

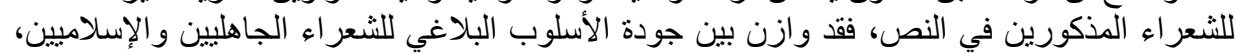

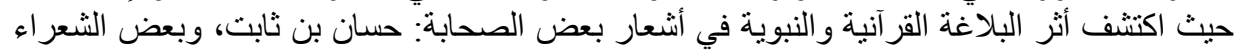

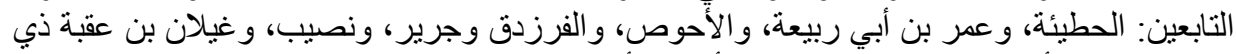

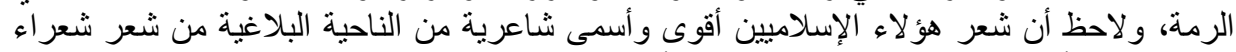

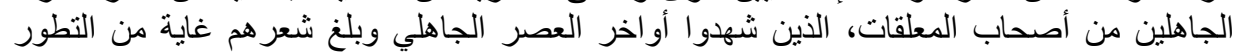

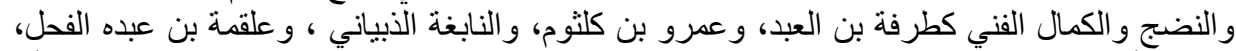

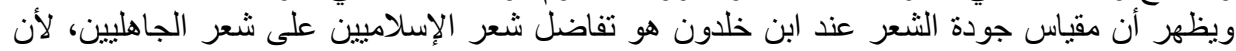

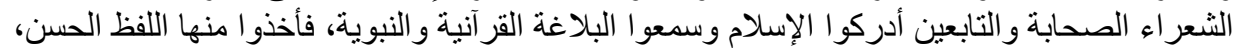

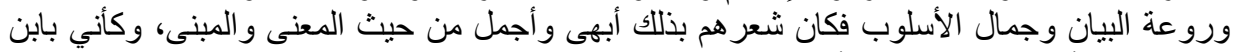

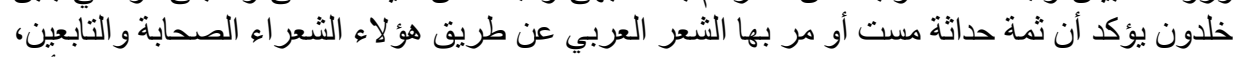

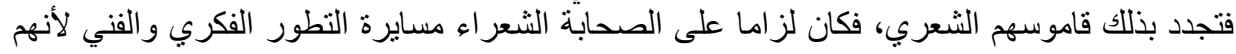




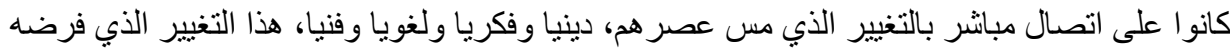

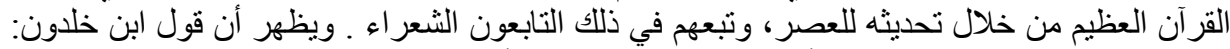

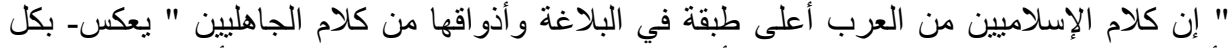

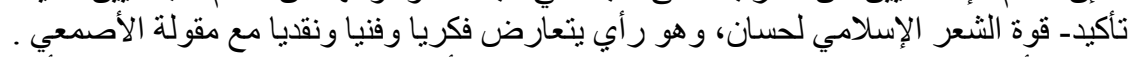

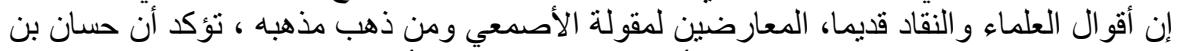

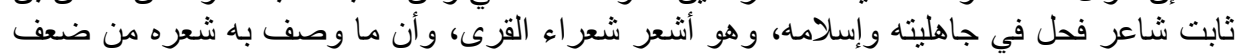

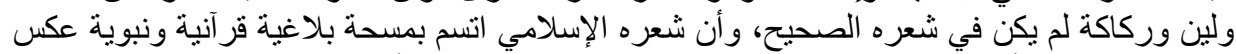

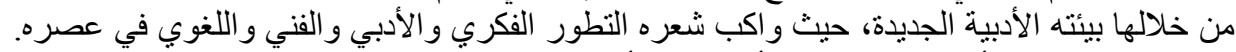

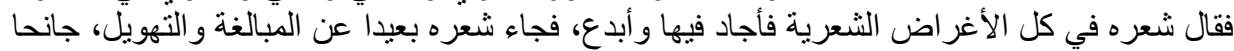

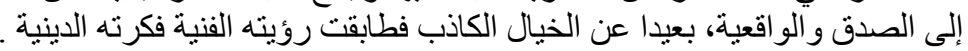

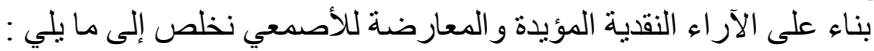

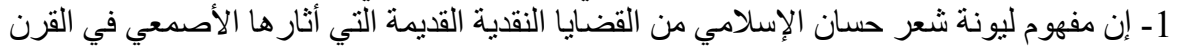

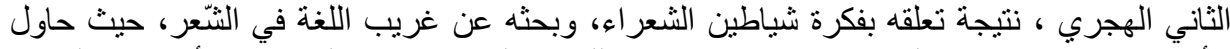

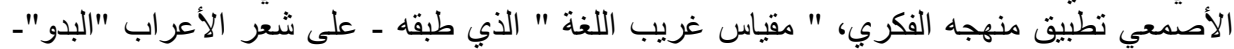

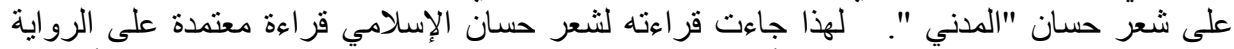

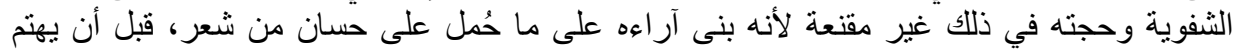

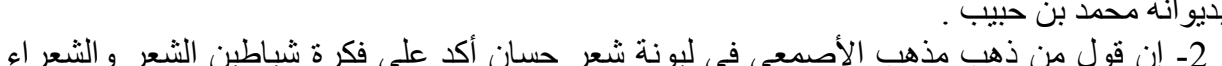

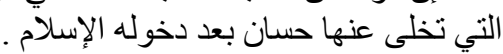

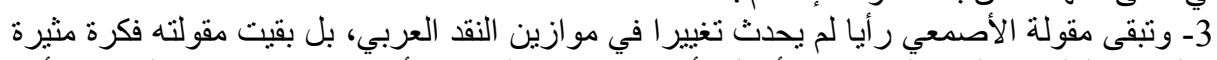

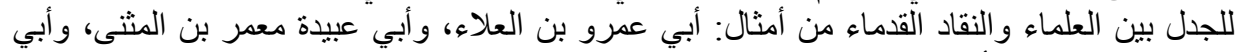

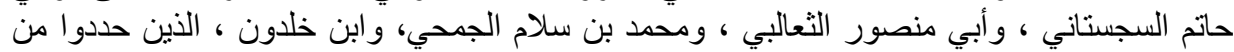

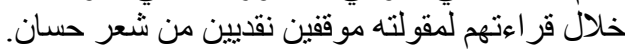

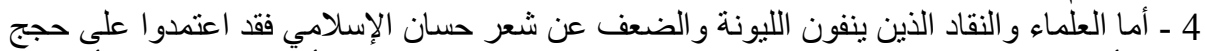

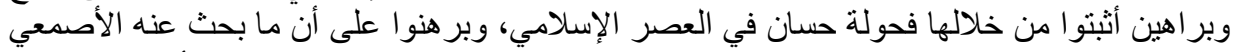
ووجده في الثعر الإسلامي لحسان، إنما هو في الثعر المنحول عليه وضعته الثران قريش لأسباب سياسية،

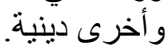

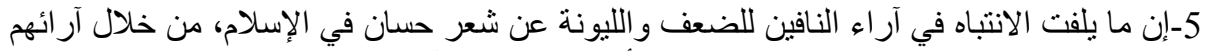

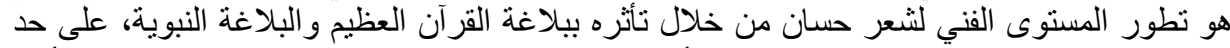

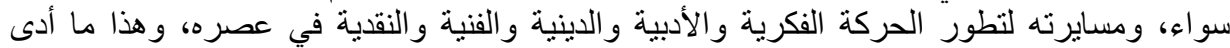

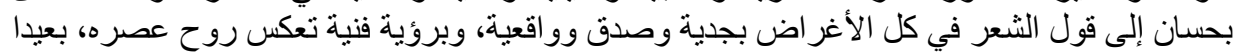

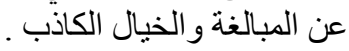

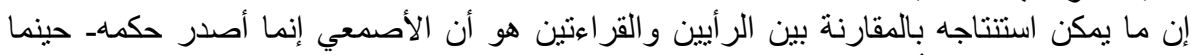

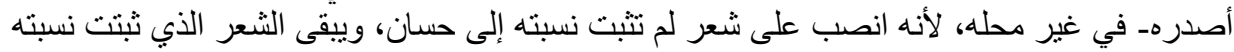
إلى حسان قويا في الجاهلة و الإسلام .

(828-740- 216 -122)*

1- أبو الفرج قدامة بن جعفر : نقد الثعر ، تحقيق وتعليق : محمد عبد المنعم خفاجي ، ط1، المكتبة

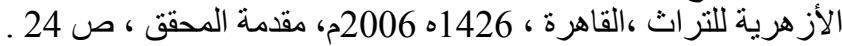

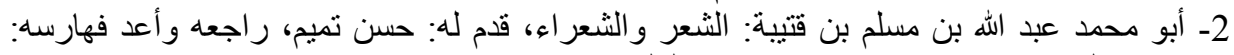

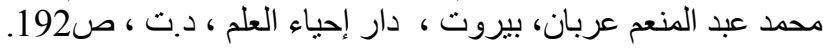




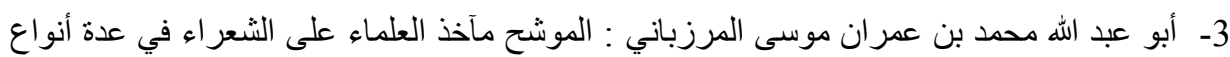

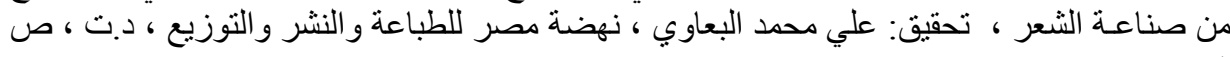
. 71

4- ابن عبد البر : (على هامش الإصابة ) الإصابة في معرفة الصحابة ، دار الغد العربي، د.ت.ج1،

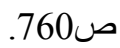

5- محمد الأزهر باي : حسان بن ثابت شاعر الجاهلية والإسلام ، مركز النشر الجامعي ، تونس ،

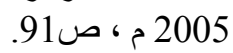
6-محمد طه الحاجري : في تاريخ النقد والهذاهب الأدبية العصر الجاهلي والقرن الأول الإسلامي ، دار

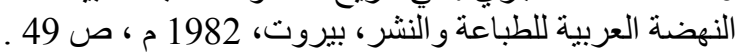

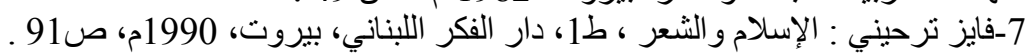

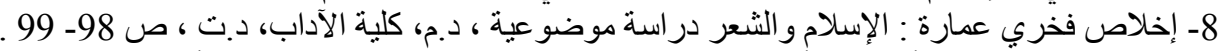

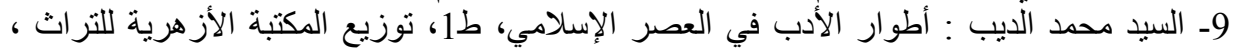

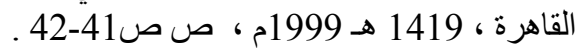
10- فؤاد أفرام البستاني : حسان بن ثابت ، سلسلة الروائع رقم 33، ط 6، منشورات دار الشروق،

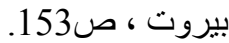
11- محمد إبراهيم جمعة : حسان بن ثابت ، في سلسلة نوابغ الفكر العربي ، ط2، دار المعارف

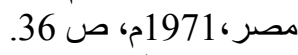

12- محمد طاهر درويش: حسان بن ثابت ، ط2 ، دار المعارف بمصر ، د.ت ، ص .506

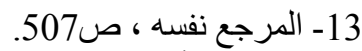

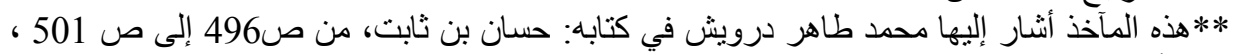

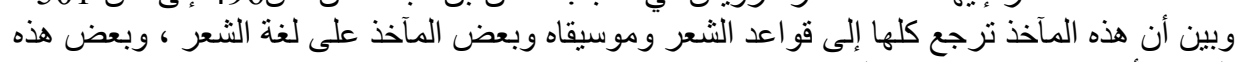

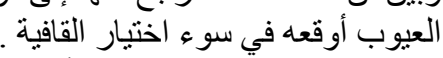
14- بهاء حسب الله : الحياة الأدبية في عصر صدر صدر الإسلام ( تاريخ و تذوق) ، ط1، دار الوفاء لدنيا

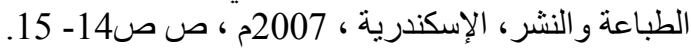
15- سامي مكي العاني : الإسلام و الثُعر، سلسلة عالم المعرفة ، الكويت ، رقم 66 6ـ 1403هـ - 1983م ص 26.

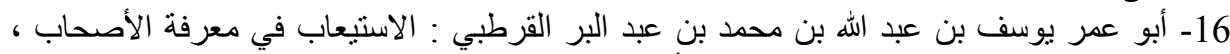

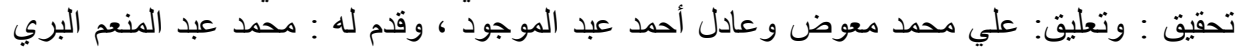

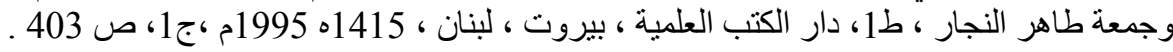

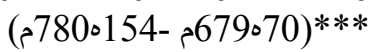
(م8200201-57280114)****

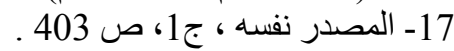

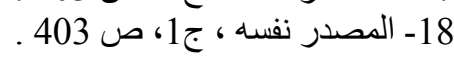

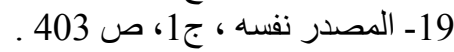

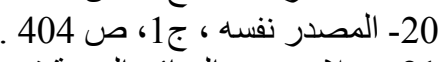
21 20 صلاح عيد : المدائح النبوية في الشعر العربي من عصر النبوة حتى البصيري ، ط1، مكتبة الآداب

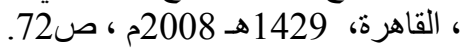
22- أبو منصور عبد الملك بن محمد ابن إسماعيل الثعالبي : كتاب خاص الخاص، قدم له : حسن أمين ،

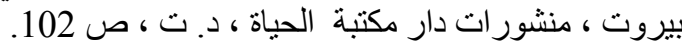

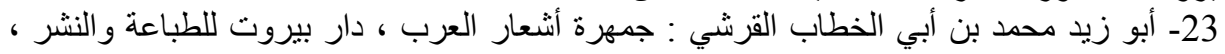

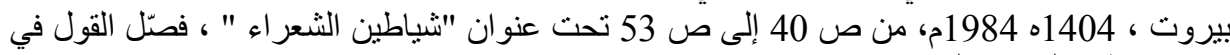

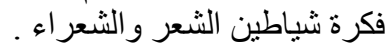


24- مسلم: صحيح مسلم، في كتاب فضائل الصحابة، 32/4، 1933، 1935. ورواه أحمد في المسند: . 219/4 301، 301 32

25- ابن سلام الجمحي : طبقات فحول الثعر اء ، قرأه وشرحه محمود محمد شاكر، دار المدني، جده ،

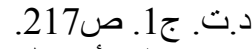

- وينظر : أبو علي الحسن بن رشيق: العمدة في محاسن الثعر و آدابه ونقده، حققه وفصله و ولقى عليه:

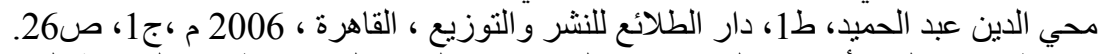

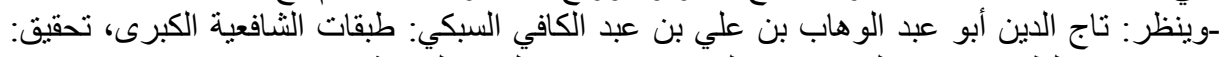

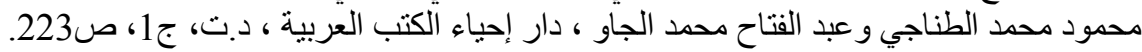

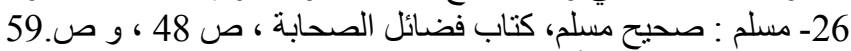

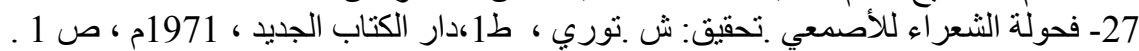

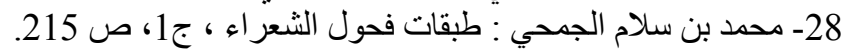

29 - محمد عبد الرحمن بن خلدون: مقدمة ابن خلدون، تقديم وتحقيق صاتيق: إيهام محمد إبر اهيم مكتبة القرآن

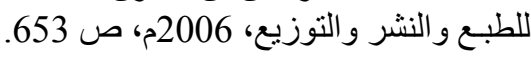

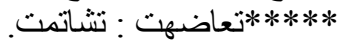

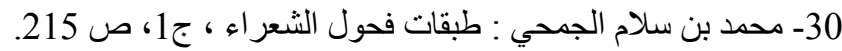

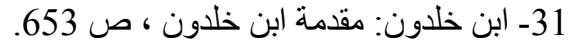

